\title{
Genome-wide transcriptional profiling uncovers a similar oligodendrocyte- related transcriptional response to acute and chronic alcohol drinking in the amygdala
}

\author{
Authors \\ Sharvari Narendra ${ }^{1,2}$, Claudia Klengel ${ }^{1}$, Bilal Hamzeh ${ }^{1}$, Drasti Patel ${ }^{2}$, Joy Otten ${ }^{1}$, Roy \\ Lardenoije $^{1}$, Emily L. Newman ${ }^{1}$, Klaus A. Miczek ${ }^{3}$, Torsten Klengel ${ }^{1}$, Kerry J. Ressler ${ }^{1}$, \\ Junghyup $\operatorname{Suh}^{1}$
}

\author{
Affiliations \\ ${ }^{1}$ Division of Depression and Anxiety Disorders, McLean Hospital, Department of Psychiatry, \\ Harvard Medical School, Belmont, MA 02478, USA \\ 2 Department of Bioinformatics, Northeastern University, Boston, MA 02115, USA \\ ${ }^{3}$ Psychology and Neuroscience Departments, Tufts University, Medford, MA 02155, USA
}

\section{Corresponding authors}

Junghyup Suh, PhD

Division of Depression and Anxiety Disorders

McLean Hospital, Harvard Medical School

Belmont, MA 02478

USA

Email: jsuh@mclean.harvard.edu

Kerry J. Ressler, MD, PhD

Division of Depression and Anxiety Disorders

McLean Hospital, Harvard Medical School

Belmont, MA 02478

USA

Email: kressler@mclean.harvard.edu 


\begin{abstract}
Alcohol intake progressively increases after prolonged consumption of alcohol, but relatively few new therapeutics targeting development of alcohol use disorder (AUD) have been validated. Here, we conducted a genome-wide RNA-sequencing (RNA-seq) analysis in mice exposed to different modes (acute vs chronic) of ethanol drinking. We focused on transcriptional profiles in the amygdala including the central and basolateral subnuclei, a brain area previously implicated in alcohol drinking and seeking, demonstrating distinct gene expression patterns and canonical pathways induced by both acute and chronic intake. Surprisingly, both drinking modes triggered similar transcriptional changes, including up-regulation of ribosome-related/translational pathways and myelination pathways, and down-regulation of chromatin binding and histone modification. Notably, multiple genes that were significantly regulated in mouse amygdala with alcohol drinking, including Atp2b1, Slc4a7, Nfkb1, Nts, and Hdac2, among others had previously been associated with human AUD via GWAS or other genomic studies. In addition, analyses of hub genes and upstream regulatory pathways predicted that voluntary ethanol consumption affects epigenetic changes via histone deacetylation pathways, oligodendrocyte and myelin function, and oligodendrocyte-related transcriptional factor, Sox17.
\end{abstract}

Overall, our results suggest that the transcriptional landscape in the central and basolateral subnuclei of the amygdala is sensitive to voluntary alcohol drinking. They provide a unique resource of gene expression data for future translational studies examining transcriptional mechanisms underlying the development of AUD due to alcohol consumption. 


\section{Introduction}

Alcohol use disorder (AUD) is a chronic relapsing brain disorder that is a major public health concern in the United States, where the lifetime prevalence of AUD among adults is nearly $30 \%$ [1]. Despite the disorder's prevalence and severity, there are few effective treatments for alcohol abuse. The hallmark of AUD is gradually increasing alcohol consumption over time [2]. This increase in alcohol intake is thought to result from neurobiological adaptation induced by alcohol [3]. Prolonged heavy alcohol exposure appears to cause progressive dysfunction in multiple brain areas, most notably changes in neuronal plasticity in the brain's reward and stress systems such as the amygdala [4].

The amygdala is comprised of multiple interconnected nuclei nested deep in the temporal lobe in human and its structures and functions are well-conserved across evolution. It has been associated with both emotion and motivation, playing an essential part in processing aversive and appetitive information [5-7]. Previous neuroimaging studies demonstrated that alcohol cues trigger amygdala activation which correlates with craving for alcohol in patients with AUD [8, 9]. In animal models, chronic alcohol exposure alters neuronal transmission in the central nucleus of the amygdala (CeA) and the neural activity of the CeA during alcohol withdrawal is associated with levels of alcohol drinking in alcohol-dependent rats $[10,11]$. Furthermore, the activation of the basolateral amygdala (BLA) and its projections to the nucleus accumbens is necessary for cue-induced alcohol seeking behaviors [12].

As alcohol has multiple direct molecular targets, identifying and characterizing genes in a brain region-specific manner is vital to our understanding of the molecular mechanisms underlying alcohol-related behaviors and AUD development and susceptibility [13-16]. Several studies have applied genomics to examine alcohol-induced transcriptional effects using chronic 
models of voluntary ethanol consumption and forced vapor exposure through ethanol vapor in rodents [17-21]. The results identified multiple molecular targets, such as alterations in neuronal function and signal transduction, indicating that chronic ethanol exposure and withdrawal have prominent actions on gene expression in multiple brain areas including the prefrontal cortex. However, these studies using microarrays with pre-determined numbers of genes and forced alcohol exposure have not directly addressed genome-wide transcriptional response to voluntary alcohol drinking. In addition, few studies investigated gene networks that are targeted by voluntary alcohol drinking in the amygdala where molecular processes may underlie the development and maintenance of alcohol-drinking and seeking behaviors [22, 23].

To acquire a better insight into gene expression alterations impacted by acute and chronic voluntary oral ethanol consumption, we employed a 2-bottle choice ethanol drinking procedure with either a single bout or chronic intermittent access that has been shown to escalate ethanol intake over weeks in female mice [24]. We then explored transcriptomic changes in the amygdala that may underly progressive increase in ethanol intake. We found that acute and chronic ethanol drinking induced similar network-level changes in gene expression, suggesting that a single episode of ethanol consumption substantially alters amygdala transcriptomes that may last for a long time. Furthermore, we identified expression networks that correlated with the level of ethanol consumption and ethanol preference, suggesting mechanistic relationships. Our bioinformatics analyses also revealed that some of the most strongly correlated genes include myelination, synaptic transmission, chromatic modification, translation, and RNA processing. Together, our findings provide systems-level evidence of the relationships between voluntary alcohol drinking and gene networks within the central and basolateral subnuclei of the amygdala. 


\section{Materials and Methods}

\section{$\underline{\text { Animals }}$}

Two separate cohorts $(\mathrm{N}=12$ for the first and $\mathrm{N}=18$ for the second cohorts $)$ of adult female C57Bl/6J mice at 7 weeks of age were purchased from Jackson Laboratories (Bar Harbor, ME) and kept under standard conditions with 12:12-hour light/dark cycle (lights on: 07:00). Animals were group housed upon arrival and acclimated for 1-2 weeks. Then, mice were individually housed and allowed access to tap water and free (ad libitum) access to standard laboratory chow during the whole experimental period. All experiments were approved by and carried out in accordance with the Institutional Animal Care and Use Committee at McLean Hospital. All experimental and animal care procedures met guidelines outlined in the NIH Guide for the Care and Use of Laboratory Animals. All efforts were made to minimize distress and the number of animals used.

\section{$\underline{\text { Alcohol drinking procedures }}$}

Twenty percent of ethanol solution (v/v) was prepared in tap water from $95 \%$ ethyl alcohol (Pharmaco-AAPER, Brookfield, CT). Mice were changed to individual housing at least 24 hours before the presentation of 2 plastic tubes of water on the cage lid for 2 days for acclimation to drinking from sipper tubes. Fluids were presented in 50-ml conical tubes (Falcon) with no. 6 rubber stoppers (\#6R, Ancare, Bellmore, NY) containing stainless steel ball-bearing sippers (TD-100, Ancare). Centrifuge tubes were securely held through the metal wire cage lid and presented to mice 2 hours before the dark cycle. Bottles were weighed to the nearest hundredth of a gram 24 hours after the fluids were given and the left/right position of the bottles were alternated before each ethanol drinking session to avoid side preferences. To control for 
spillage and evaporation, daily "drip" averages (loss of fluid in two cages with no animal present) were subtracted from individual fluid intakes. Mice were also weighed weekly to the nearest tenth of a gram to calculate the grams of ethanol intake per kilogram of body weight. Preference for ethanol was calculated for ethanol compared with water, with formula being volume of ethanol intake (ml) divided by total volume fluid intake (ml).

Mice from each cohort were assigned to three drinking groups. Mice in the acute drinking group (Acute Drinking) were given two bottles of water for 27 days, then a bottle with $20 \%$ ethanol and a bottle with water on Day 28. The chronic intermittent access drinking group (Chronic Drinking) of mice received free-choice 24 -hour access to $20 \%$ ethanol and water on every-otherday (EOD) basis for 4 weeks (28 days). Mice in the water drinking group (Water Drinking) received the same schedule of total fluid access but consumed only water from two bottles. After completion of the experiments on day 29, at 1-2 hours after lights on, mice were deeply anesthetized with isoflurane and sacrificed by decapitation. Trunk blood was collected in EDTA tubes to measure blood ethanol concentration (BEC), and vaginal smear was collected on noncoated glass microscope slides to determine the stage of the estrous cycle. Brains were rapidly removed from skull, and placed on dry ice, and stored at $-80{ }^{\circ} \mathrm{C}$ until further processing. Fresh frozen brains were sectioned at a thickness of $300 \mathrm{um}$, then micropunches $(1 \mathrm{~mm}$ in diameter and $1 \mathrm{~mm}$ in thickness) were bilaterally collected from the entire amygdala including basolateral amygdala (BLA) and central amygdala (CeA) based on established anatomical coordinates from the mouse brain atlas [25]. The micropunches were aimed to include the following coordinates: $\mathrm{ML} \pm 3.2, \mathrm{AP}-1.5, \mathrm{DV}-5.0 \mathrm{~mm}$, and all the samples were placed in microcentrifuge tubes $(1.5 \mathrm{ml})$ kept frozen in dry ice, and stored at $-80 \mathrm{C}$ until RNA isolation. BEC was determined using the 
Analox Analyzer (Analox Instruments Inc., Lunenburg, MA) from blood samples (30 ul). The vaginal cytology was carried out using crystal violet staining [26].

$\underline{\text { RNA extraction and sequencing }}$

Total RNA was isolated and purified using the Absolutely RNA Miniprep Kit (Cat\# 400800, Agilent Technologies, Santa Clara, CA, USA) according to the manufacturer's protocol for extremely small samples. Quality and concentration of the extracted RNA were evaluated using a NanoDrop 8000 spectrophotometer (Thermo Scientific). Eleven samples from the first batch (4 from Water, 4 from Acute and 3 from Chronic Drinking groups) and 17 samples from the second batch (6 from Water, 5 from Acute and 6 from Chronic Drinking groups) were sent to Beijing Genomics Institute (Hong Kong, China). Library construction and whole genome sequencing were conducted on BGISEQ-500 platform using the DNBseq short-read $100 \mathrm{bp}$ paired-end reading.

\section{$\underline{\text { Data Processing }}$}

Raw sequencing reads were quality assessed with FastQC (https://www.bioinformatics.babraham.ac.uk/projects/fastqc/) (Babraham Institute, Cambridge, UK). Salmon [27] was used to first build a transcriptome index using the reference transcriptome for Mus musculus (GRCm38/mm10) along with the non-coding RNAs of the same, and then to quantify the RNA-seq samples at the transcript level. The R package, tximport, [28] was used to import this transcript-level abundance generated by Salmon, the estimated counts and the corresponding transcript lengths, and summarize it into transcript-level 
and gene-level expression matrices. Gene-level expression matrix was generated using the GENCODE mouse annotation (www.gencodegenes.org) as reference (release M21).

\section{Estimation of cell type abundances}

Cell type abundances were estimated with BRETIGEA, an R package [29], for each of the following cell types - neuron, oligodendrocyte, microglia, oligodendrocyte precursor cell, astrocytes, and endothelial cell. BRETIGEA contains thoroughly validated datasets containing brain cell type-specific marker genes. Using the 'brainCells' function, with the filtered dataset containing 16,260 genes as input, a sample-by-cell type matrix of estimated cell type proportion variables were generated.

\section{Differential expression}

ComBat-seq [30] was used to adjust the batch effect by keeping the negative binomial distribution of RNA-seq reads count and the integer nature of the data. A pre-filtering step was then applied to the corrected gene counts where genes with less than ten counts on average across all the samples were filtered out, after which 16,260 genes were retained for the subsequent analysis. The R package DESeq2 [31] was used for downstream differential expression analysis using default parameters. The readings were then normalized using DESeq2 with the means of normalized counts as a filter statistic. In the initial data exploration, principal component analysis (PCA) was constructed to calculate the coefficient of variation between groups directly using 'plotPCA', a functionality in DESeq2.

Functional and Pathway Enrichment Analysis of DEGs 
The lists of DEGs were first divided into two sets, up- and down-regulated, with the criteria of $\mathrm{p}$-value cutoff $<0.05$, which was set to increase the number of genes in each condition. Then, function and pathway enrichment analysis were performed using the $\mathrm{R}$ package, clusterProfiler [32]. Gene ontology (GO) analysis provided gene annotations in biological processes (BP), molecular functions (MF), and cellular components (CC). In addition, Kyoto Encyclopedia of Genes and Genomes (KEGG) analysis provided more information on biological pathways related to diseases and drug targets.

\section{GWAS Catalog and DisGeNET analysis}

To obtain a better understanding of whether the significant genes obtained in this study were already implicated in previously published alcohol addiction studies, the list of significant genes from the DESeq2 analysis was compared with the list of significant genes in GWAS Catalog (www.ebi.ac.uk/gwas) and DisGeNET (www.disgenet.org) datasets. The "All associations v1.0.2 - with added ontology annotations, GWAS Catalog study accession numbers and genotyping technology" dataset from the GWAS Catalog website and the "ALL gene-disease associations" dataset from the DisGeNET website were first downloaded and analyzed in R. From the GWAS Catalog dataset, the columns of interest "DISEASE/TRAIT" and “MAPPED_GENE” were retained, while from the DisGeNET dataset, "geneSymbol" and "diseaseName" were retained. The analysis was performed with disease terms containing "alcohol" from both "DISEASE/TRAIT" and "diseaseName" columns, after which, the disease terms containing "nonalcohol/non-alcohol" were filtered out. The significant genes from the DESeq2 analysis were then matched with the resulting genes from both the GWAS Catalog and DisGeNET datasets, to get the overlapping/common genes. 
Identification of Hub genes and Regulatory Transcription Factors

To visualize protein-protein interactions networks among DEGs, the Search Tool for the Retrieval of Interacting Genes (STRING) online database (version 11.0) [33] was used with DEGs with the criteria of adjusted p-value cutoff $<0.05$. The same sets of DEGs were also used with GeneGo MetaCore (Clarivate Analytics, PA, USA) to detect upstream transcription factors. The Transcriptional Regulatory Relationships Unraveled by Sentence-based Text mining (TRRUST) (version 2) [34] online database was also utilized to discover transcriptional regulatory networks.

cDNA synthesis and quantitative PCR (qPCR)

RNA samples were reverse transcribed into cDNA using superscript IV kit (cat\# 18091200, Thermo Scientific, Waltham, MA) using random hexamer primers. Complementary DNA was amplified on a ViiA7 Real-Time PCR system (Thermo Scientific) with POWRUP SYBR Green Master Mix (cat\# 4368706Thermo Scientific). Primers for genes of interest and housekeeping gene $A c t b$ were as follows: $B c 1$ (fwd. 5' GGTCCTCAGCTCTGGAAAAA 3'; rev. 5' AGGTtGTGTGTGCCAGTTACC 3'), Btg2 (fwd. 5' GCGAGCAGAGACTCAAGGTT 3'; rev. 5' CCTtTGGAtGgtTTtTCTGG 3'), Haghl (fwd. 5' GGACTCACCAGCCCTCTTCT 3'; rev. 5' TTGGCCAAGCTCTGGTACAT 3'), Kdm3a (fwd. 5' CATTGGAGCAAAACTTCCTCA 3'; rev. 5' TGGTTTTGTTCTCGGTACTTCA 3'), Lrrc24 (fwd. 5' GCTGGATTTCACCTTCTTGC 3'; rev. 5' GCCTGGTCCTCCAGTAATTC 3'), Nenf (fwd. 5' GGATCCAGCAGACCTCACTC 3'; rev. 5' TGGCTTTGTACACCTTGCTG 3'), Nts (fwd. 5'TCCAGCTCCAGAAAATCTGC 3'; rev. 5'CCTTCTCGTTTTTATCATTGACG 3'), and Actb (fwd. 5' 
CCAACCGTGAAAAGATGACC 3'; rev. 5'ACCAGAGGCATACAGGGACA 3'). Specificity

of the qPCR reaction was confirmed with melt curve analysis to ensure that only the expected PCR product was amplified. Duplicates were run for each reaction, and $\mathrm{Ct}$ values were normalized using the established delta-delta $\mathrm{Ct}$ method $(2-\Delta \Delta \mathrm{Ct})$ and then normalized to $A c t b$ Cts.

$\underline{\text { Statistical analysis }}$

Data were analyzed using R or Graphpad Prism (version 9.1, GraphPad Software, San Diego, CA). The level of significance was set at $\mathrm{p} \leq 0.05$, and results are presented as mean plus or minus standard error of the mean $(M \pm \mathrm{SEM})$. For the drinking data, ethanol intake $(\mathrm{g} / \mathrm{kg})$, volume $(\mathrm{ml})$ of water and ethanol consumed, total fluid intake $(\mathrm{ml})$, ethanol preference $(\%)$, and body weight $(\mathrm{g})$ were analyzed with multiple two-way analyses of variance (ANOVAs), followed by Bonferroni post hoc analysis when significant group effects were found $(\mathrm{p}<0.05)$. BEC (mg/dl) and single daily ethanol intake $(\mathrm{g} / \mathrm{kg})$ on day 29 between Acute and Chronic Drinking groups were analyzed with one-way ANOVA.

\section{Results}

\section{2-bottle choice drinking}

We employed a well-established 2-bottle choice drinking paradigm [24] and divided mice into 3 drinking groups (Water, Acute and Chronic EtOH) (Figure 1a). Ethanol intake of the first cohort was slightly higher than that of the second cohort in both Acute and Chronic Drinking groups but the small difference was not statistically significant. Consistent with previous 
behavioral studies [24, 35], mice in the Chronic Drinking group increased ethanol intake across the first 2-week period, subsequently maintaining a stable level (a daily average of $23.38 \pm 0.78$ $\mathrm{g} / \mathrm{kg}$ in weeks 3-4). On day 28, mean ethanol intake was $20.96 \pm 2.00 \mathrm{~g} / \mathrm{kg}$ for the Chronic Drinking group, which was significantly higher $(p<0.05)$ than that of the Acute Drinking group $(11.41 \pm 1.54 \mathrm{~g} / \mathrm{kg})$ (Figure 1b). As expected, there were no differences in total liquid consumption across 4 weeks among the groups (Figure 1c). Consequently, analysis of 24-hour preference values revealed that mice in the Chronic Drinking group showed increased preference as early as after 2 weeks of intermittent drinking, which was sustained at an average $72.60 \%$ in weeks 3-4. In contrast, mice in the Acute Drinking group displayed $45.98 \%$ preference on Day 28 (Figure 1d). During 4 weeks of the drinking period, body weight (g) did not show any significant group differences on day 1 (Water, $19.60 \pm 0.51$; Acute, $19.63 \pm 0.36$; Chronic, 19.71 \pm 0.32 ) and day 29 (Water, $20.83 \pm 0.47$; Acute, $20.54 \pm 0.23$; Chronic, $20.81 \pm 0.41$ ). On the final day of the study, all the mice in each drinking group were in either proestrus or estrus phase of the estrous cycle. There is no difference in alcohol consumption between mice in different phases, which is consistent with previous findings that alcohol intake is not affected by estrous cycle phase in female rodents $[36,37]$. These data demonstrate that our protocol succeeded in achieving standard levels of both acute and chronic drinking behaviors and metabolism for subsequent transcriptional profiling of amygdala function.

\section{$\underline{\text { RNA-seq analysis }}$}

Since acute and chronic excessive alcohol consumption leads to gene expression alterations and cellular adaptations, RNA sequencing (RNA-seq) analysis was used to determine genome-wide transcriptomic profiles. Given the important roles of central amygdala $(\mathrm{CeA})$ and 
basolateral amygdala (BLA) in alcohol-related synaptic changes and behaviors, we collected micropunches containing these subnuclei from three Drinking groups: Water, Acute and Chronic EtOH (Figure 2a). Since we collected RNA samples from two independent cohorts of mice, we first used Combat-seq [30] to adjust for any batch effects by keeping the negative binomial distribution of RNA-seq reads count and the integer nature of the data. Then, among 16,260 genes detected in the results, we assessed overall similarity among the samples by utilizing an unsupervised classification method, principal component analysis (PCA), and confirmed no outliers isolated by experimental conditions along two first principal components with $55 \%$ of the total variance (Figure 2b). Furthermore, since differences in cell type proportions can be a major source of variation in gene expression profiles, we used a computational cell type deconvolution tool, BRETIGEA [29] to estimate the abundances of six relevant cell types, including neurons, astrocytes, microglia, oligodendrocyte precursor cells (OPC), oligodendrocytes, and endothelial cells. We found no significant differences in any of the assessed cell types (Figure 2c). Together, these findings suggest that most of the observed variation in gene expression can be attributed to molecular implications of alcohol consumption rather than other confounding factors.

To identify genes exhibiting significantly altered expression due to alcohol drinking, we next calculated the expression level of each transcript based on the number of transcripts per million reads, followed by normalization of reads. Initially, using the DESeq2 package [31] with parameters of $p<0.05$ and $\mid \log ($ fold change $) \mid>0$, we identified 1300 and 1384 differentially expressed genes between Acute and Water drinking groups and between Chronic and Water drinking groups, respectively (Figure $3 \mathrm{a}$ and $\mathrm{b}$ ). Then, we used the more stringent false discovery rate (FDR)-adjusted p-value cutoff of 0.05 to trim potential false positive results. We 
further identified 30 (Acute vs. Water, up-regulated: 23 and down-regulated: 6) and 97 (Chronic vs. Water, up-regulated: 36 and down-regulated: 61) differentially expressed genes (Figure 3c and Table 1,2). These studies identified a number of robustly and significantly differentially expressed genes in the amygdala as a result of acute or chronic ethanol voluntary drinking.

\section{$\underline{\text { GO and KEGG Gene Enrichment Analyses }}$}

To further identify networks of coordinately regulated genes that might point to alcoholrelated specific biological functions, we next performed Gene Ontology (GO) and Kyoto Encyclopedia of Genes and Genomes (KEGG) Pathway enrichment analyses. We found that the primary effects of acute and chronic alcohol drinking were related to ribosome, cytoplasmic translation, chromatin binding, and histone modification pathways (Figure 4 and Figure 5). Interestingly, among those GO enrichment terms, "myelin sheath" (FDR-adjusted p $=0.0003$ ) was in the top 5 up-regulated pathways, suggesting alcohol drinking affects molecular and cellular mechanisms underlying oligodendrocyte maturation and myelination, consistent with previous reports that demonstrated glial dysfunction in AUD pathophysiology [38]. These findings suggest that chronic alcohol drinking induces neuroadaptations mediated by gliaspecific molecular alterations in the amygdala.

\section{Identification of the potential regulatory pathways}

To identify a list of hub genes, we next used STRING, a common online database for predicting protein-protein interaction networks. It revealed hub genes with 4-5 nodes, including histone deacetylase 2 (Hdac2), heterogeneous nuclear ribonucleoprotein M (Hnrnpm), histone deacetylase complex subunit $\sin 3 \mathrm{a}(\operatorname{Sin} 3 a)$, and chromodomain helicase DNA binding protein 1 
(Chd1), particularly in Chronic Drinking condition (Figure 6). The Hdac2, Sin3a and Chdl are members of proteins associated with histone deacetylase activity. We then applied DEGs to the GeneGo MetaCore online database and identified 4 and 17 candidate upstream regulatory transcription factors in Acute and Chronic Drinking conditions, respectively (Table 3). SRY (sex determining region Y)-box transcription factor 17 (Sox17) stood out in both Acute and Chronic Drinking conditions. Since Sox 17 has been shown to regulate oligodendrocyte progenitor cell expansion and differentiation, this finding is consistent with our results from GO/KEGG pathway analyses, particularly "myelin sheath" (Figure 4 and 5). In addition, chronic drinking seems to drive multiple transcription factors including cAMP responsive element binding protein 1 (Creb1), which has been well-known to be involved in fear memory processing and alcohol exposure. Together, the findings suggest that voluntary alcohol consumption affects epigenetic changes via histone deacetylation pathways, and oligodendrocyte-related transcriptional factor, Sox 17.

\section{GWAS catalog and DisGeNET}

To determine if our DEGs (adjusted $\mathrm{p}<0.05$ ) are associated with AUD, we used online genomewide association studies (GWAS) catalog database. We found that 5 of our DEGs, including ATPase plasma membrane calcium transporting 1 (Atp2b1), heat shock protein family A member 4 (Hspa4), strawberry notch homolog 1 (Sbno1), solute carrier family member 7 (Slc4a7), and UBX domain protein $2 \mathrm{~b}(U b x n 2 b)$, from the Chronic Drinking group have previously been identified in GWAS of AUD.

To further compare our DEGs with previously reported findings in AUD, we also took advantage of the publicly available databases DisGeNET. We found that nuclear factor kappa B 
subunit $1(N f k b 1)$ and neurotensin $(N t s)$ from Acute Drinking group have been previously linked to AUD. Similarly, beside 5 DEGs identified from GWAS, we found 5 more DEGs, including calcium/calmodulin dependent protein kinase IV (Camk4), energy homeostasis associated (Enho), Hdac2, LDL receptor related protein 6 (Lrp6), Slc4a7, and SLIT and NTRK like family member 2 (Slitrk2)), which were previously linked to AUD in the literature.

\section{Validation of DEGs by qPCR}

Seven genes including brain cytoplasmic RNA 1 (Bc1), BTG anti-proliferation factor 2 (Btg2), hydroxyacylglutathione hydrolase like (Haghl), leucine rich repeat containing 24 (Lrrc24), neudesin neurotrophic factor (Nenf), and lysine demethylase 3A ( $K d m 3 a)$ were used for qPCR analysis to validate the expression profiles obtained by bulk RNA-seq (Table 4). Consistent with the RNA-seq findings, in all cases, the relative fold change of gene expression was in the same direction in Acute and Chronic drinking groups.

\section{Discussion}

We have characterized the transcriptome level response to acute and chronic intermittent ethanol drinking with a 2-bottle choice drinking procedure, and identified sets of significant DEGs, distinct GO and KEGG pathways, hub genes, and upstream transcriptional factors that are sensitive to ethanol drinking in the mouse amygdala. Our results demonstrate that both acute and chronic ethanol drinking can impact on similar biological processes including translational machinery, epigenetic modifications, synaptic plasticity, and neurological disorders in the amygdala. Many of the genes identified in this mouse model of amygdala transcriptional 
regulation with alcohol had previously been associated with human AUD via GWAS or other genomic approaches, supporting the use of this model for translational, mechanistic studies. Furthermore, the findings also add to a body of evidence indicating that ethanol exposure leads to molecular and cellular alterations in non-neuronal cell types, such as oligodendrocytes.

Notably, we did not observe FDR-significant differences in DEGs and GO/KEGG pathways between Acute and Chronic drinking groups. A single bout of voluntary ethanol consumption resulted in molecular changes in the amygdala similar to those altered by repeated alcohol drinking, suggesting that acute ethanol drinking is sufficient to trigger critical molecular adaptations, possibly leading to future addiction with repeated alcohol exposure. As acute behavioral responses to alcohol have predictive value regarding risk for long-term alcohol drinking behavior in humans [39] and animal models [40], our results indicate striking overlapping regulation of amygdala-specific gene expression by alcohol regardless of the number of drinking episodes.

Many of the genes we identified were of great interest given prior findings. Notably, neurotensin (Nts) and its receptors have been implicated as contributing to the behavioral effects of alcohol in animal models. Chronic ethanol exposure increased Nts expression in the dorsal striatum [41], whereas ethanol decreased the expression of Nts receptors in both the nucleus accumbens (NAcc) and midbrain [42]. Furthermore, recent work has demonstrated that Ntsexpressing neurons in the CeA contribute to the voluntary consumption of alcohol [43]. These findings are consistent with our results indicating an increase in Nts expression in Acute Drinking group, as the micropunches included the CeA in our samples. Interestingly, our recent studies demonstrated that the Nts receptor $2(\mathrm{Ntsr} 2)$ is highly expressed in the BLA Thy1+ neurons that strongly project to the NAcc [44]. Therefore, our result provides a novel insight at a 
circuit level into how the amygdala subnuclei, CeA-Nts and BLA-Ntsr2, may interactively mediate voluntary and cue-induced alcohol drinking behaviors.

Our study revealed many other well-known pathways affected by alcohol drinking. Amongst these, first, translational machinery including rRNA binding, ribosome and ribosomal subunits seems to be positively affected by alcohol drinking. Consistent with previous studies from different brain areas [45], these results suggest that alcohol exposure also similarly affects translation of proteins in the amygdala, and ultimately leads to neuroadaptation via reorganization of synaptic structures, synaptic proteins and neurotransmitter receptors, such glutamate and GABA receptors [45]. Second, we found several enrichment terms related to chromatin remodeling, histone modification and DNA methylation in GO/KEGG analyses. Similarly, we also identified hub genes, mostly involved in histone deacetylation activity, including $H D A C 2$. It was recently shown that there is increased HDAC2 level and activity in the amygdala of $P$ rats, an alcohol-preferring rat line, and acute ethanol injection decreased HDAC2 activity and subsequently reduced voluntary ethanol intake [46]. These results suggest that alcohol drinking affects gene expression by potentially regulating epigenetic alterations, particularly histone modifications via HDAC2. Third, we found that pathways related to neurodegenerative diseases, including Huntington disease and Parkinson disease, are enriched in the KEGG analysis. Since the brain is a major target for the actions of alcohol, and heavy alcohol consumption has long been associated with brain damage as a risk factor [47], our study also confirms that alcohol consumption triggers similar molecular pathological pathways involved in neurodegenerative diseases. Fourth, one of interesting GO terms in our analysis is "myelin sheath." Since our estimation of different cell types did not detect any discrepancy between samples from different drinking groups, the findings indicate that gene expression 
involved in myelin sheath formation and maintenance is affected by alcohol drinking.

Interestingly, this pathway was up-regulated in both the Acute and Chronic Drinking groups, suggesting that a potential molecular recovery mechanism may be activated following myelination damages after alcohol drinking.

While genes are co-expressed forming functional networks, identifying upstream regulators of these genes and networks can provide insight into cellular function and lead to a potential therapeutic intervention. In our study, we observed that many of the DEGs from Acute and Chronic groups are regulated by Sox 17. Since Sox 17 regulates OPC proliferation and differentiation to oligodendrocytes via Wnt/ $\beta$-catenin signaling pathway $[48,49]$, alcohol drinking seems to directly impact Sox17 transcription factor and OPC and consequently myelination in the amygdala. Notably, our group previously reported that amygdala-dependent Wnt/ $\beta$-catenin signaling pathway is also involved in fear memory consolidation [50]. Together these data, along with the above myelin sheath findings in our pathway analyses, provides strong evidence for a role of oligodendrocyte alterations in the aftermath of ethanol consumption.

In summary, we identified alcohol-sensitive amygdala-associated candidate genes and pathways targeted by measuring genome-wide transcriptomic analyses. Consistent with previous gene expression studies, we found that voluntary alcohol consumption, regardless the number of drinking episodes, results in similar gene expression changes in ribosome-related/translational pathways, myelination, chromatin-binding, and histone modification. These genes and pathways suggest convergence of human GWAS and molecular studies with amygdala transcription data from mouse drinking models. Future studies will use advanced cell targeting techniques to validate the roles of identified genes in neural adaptation processes mediating the progression from acute to chronic alcohol intake. 


\section{Figure titles and legends}

\section{Figure 1. Experimental design and fluid consumption levels.}

(a) Experimental design and timeline. (b) Ethanol intake (g/kg BW) over 24 hours on water/20\%

EtOH drinking days. (c) Water intake over 24 hours on water/water drinking days. (d) EtOH preference ratios. (e) Blood ethanol concentration (mg/dl) measured in Acute and Chronic Drinking groups of 2nd cohort of mice on Day 28. (f) Correlation of BEC to the amount of ethanol consumed by mice in Acute and Chronic Drinking groups on Day 28. Data are mean \pm SEM. $* * p<0.01$ difference between groups.

\section{Figure 2. Initial assessment of sequencing results.}

(a) Diagram for amygdala tissue collection. (b) PCA plot showing no separation on alcohol drinking condition over the first two principal components, explaining $55 \%$ of the variation in total. (c) Bar graphs showing the estimated cell type abundance for seven relevant cell types as determined by cell type deconvolution analysis. Each bar represents a single sample.

\section{Figure 3. Differential gene expression analysis.}

(a) Volcano plot showing the fold change and adjusted p-value for each gene. Genes with significant up-regulation ( $\mathrm{p}$ adjusted $<0.05$ ) in Acute Drinking group (left) and Chronic Drinking group (right) are colored in magenta, and genes with significant down-regulation are colored in green. (b) Overlap Venn Diagrams of differentially expressed genes (DEGs) for comparisons across all drinking groups. P-adjusted value cutoff $=0.05$.

Figure 4. GO enrichment and KEGG pathway analysis of DEGs in response to Acute alcohol drinking.

The ordinate represents the GO or KEGG terms, the upper abscissa indicates the number of genes in the GO/KEGG terms, and the lower abscissa indicates the level of significance of the 
enrichment (gray bar, FDR $=0.01)($ a) Genes were categorized with the Biological Process domain. (b) Genes were categorized with the Cellular Component domain. (c) Genes were categorized with the Molecular Function domain. (d) The top 5 enriched pathways in the KEGG pathway analysis (gray bar, FDR $=0.01$ ).

Figure 5. GO enrichment and KEGG pathway analysis of DEGs in response to Chronic

\section{alcohol drinking.}

The ordinate represents the GO or KEGG terms, the upper abscissa indicates the number of genes in the GO/KEGG terms, and the lower abscissa indicates the level of significance of the enrichment (gray bar, FDR $=0.01)($ a) Genes were categorized with the Biological Process domain. (b) Genes were categorized with the Cellular Component domain. (c) Genes were categorized with the Molecular Function domain. (d) The top 5 enriched pathways in the KEGG pathway analysis (gray bar, FDR $=0.01$ ).

Figure 6. The protein-protein interaction (PPI) network analysis using STRING database. The 97 DEGs from the Chronic drinking group were input into STRING database and archived 95 nodes and 38 edges, with PPI enrichment $p$-value $<0.00352$. 


\section{References}

1. McCabe, S.E., et al., Multiple DSM-5 substance use disorders: A national study of US adults. Hum Psychopharmacol, 2017. 32(5).

2. Schmidt, W. and R.E. Popham, Heavy alcohol consumption and physical health problems: a review of the epidemiological evidence. Drug Alcohol Depend, 1975. 1(1): p. 27-50.

3. Ron, D. and S. Barak, Molecular mechanisms underlying alcohol-drinking behaviours. Nat Rev Neurosci, 2016. 17(9): p. 576-91.

4. Koob, G.F., A role for brain stress systems in addiction. Neuron, 2008. 59(1): p. 11-34.

5. Parsons, R.G. and K.J. Ressler, Implications of memory modulation for post-traumatic stress and fear disorders. Nat Neurosci, 2013. 16(2): p. 146-53.

6. Janak, P.H. and K.M. Tye, From circuits to behaviour in the amygdala. Nature, 2015. 517(7534): p. 284-92.

7. McCullough, K.M., F.G. Morrison, and K.J. Ressler, Bridging the Gap: Towards a cell-type specific understanding of neural circuits underlying fear behaviors. Neurobiol Learn Mem, 2016. 135: p. 27-39.

8. Yan, P. and C.S. Li, Decreased amygdala activation during risk taking in non-dependent habitual alcohol users: A preliminary fMRI study of the stop signal task. Am J Drug Alcohol Abuse, 2009. 35(5): p. 284-9.

9. Zhang, L., et al., Smaller right amygdala in Caucasian alcohol-dependent male patients with a history of intimate partner violence: a volumetric imaging study. Addict Biol, 2013. 18(3): p. 537-47.

10. de Guglielmo, G., et al., Recruitment of a Neuronal Ensemble in the Central Nucleus of the Amygdala Is Required for Alcohol Dependence. J Neurosci, 2016. 36(36): p. 9446-53.

11. Roberto, M. and G.R. Siggins, Nociceptin/orphanin FQ presynaptically decreases GABAergic transmission and blocks the ethanol-induced increase of GABA release in central amygdala. Proc Natl Acad Sci U S A, 2006. 103(25): p. 9715-20.

12. Chaudhri, N., et al., Unilateral inactivation of the basolateral amygdala attenuates context-induced renewal of Pavlovian-conditioned alcohol-seeking. Eur J Neurosci, 2013. 38(5): p. 2751-61.

13. Wolen, A.R. and M.F. Miles, Identifying gene networks underlying the neurobiology of ethanol and alcoholism. Alcohol Res, 2012. 34(3): p. 306-17.

14. Mulligan, M.K., et al., Toward understanding the genetics of alcohol drinking through transcriptome meta-analysis. Proc Natl Acad Sci U S A, 2006. 103(16): p. 6368-73.

15. Kerns, R.T., et al., Ethanol-responsive brain region expression networks: implications for behavioral responses to acute ethanol in DBA/2J versus C57BL/6J mice. J Neurosci, 2005. 25(9): p. 2255-66.

16. Mayfield, R.D., et al., Patterns of gene expression are altered in the frontal and motor cortices of human alcoholics. J Neurochem, 2002. 81(4): p. 802-13.

17. Osterndorff-Kahanek, E.A., et al., Chronic ethanol exposure produces time- and brain region-dependent changes in gene coexpression networks. PLoS One, 2015. 10(3): p. e0121522. 
18. Smith, M.L., et al., Time-Course Analysis of Brain Regional Expression Network Responses to Chronic Intermittent Ethanol and Withdrawal: Implications for Mechanisms Underlying Excessive Ethanol Consumption. PLoS One, 2016. 11(1): p. e0146257.

19. Bogenpohl, J.W., et al., Cross-Species Co-analysis of Prefrontal Cortex Chronic Ethanol Transcriptome Responses in Mice and Monkeys. Front Mol Neurosci, 2019. 12: p. 197.

20. Ferguson, L.B., et al., Dissecting Brain Networks Underlying Alcohol Binge Drinking Using a Systems Genomics Approach. Mol Neurobiol, 2019. 56(4): p. 2791-2810.

21. Melendez, R.I., et al., Brain region-specific gene expression changes after chronic intermittent ethanol exposure and early withdrawal in C57BL/6J mice. Addict Biol, 2012. 17(2): p. 351-64.

22. Kyzar, E.J., H. Zhang, and S.C. Pandey, Adolescent Alcohol Exposure Epigenetically Suppresses Amygdala Arc Enhancer RNA Expression to Confer Adult Anxiety Susceptibility. Biol Psychiatry, 2019. 85(11): p. 904-914.

23. Sakharkar, A.J., et al., Altered amygdala DNA methylation mechanisms after adolescent alcohol exposure contribute to adult anxiety and alcohol drinking. Neuropharmacology, 2019. 157: p. 107679.

24. Hwa, L.S., et al., Persistent escalation of alcohol drinking in C57BL/6J mice with intermittent access to 20\% ethanol. Alcohol Clin Exp Res, 2011. 35(11): p. 1938-47.

25. Franklin, K.B.J. and G. Paxinos, Paxinos and Franklin's The mouse brain in stereotaxic coordinates. 2013.

26. Cora, M.C., L. Kooistra, and G. Travlos, Vaginal Cytology of the Laboratory Rat and Mouse: Review and Criteria for the Staging of the Estrous Cycle Using Stained Vaginal Smears. Toxicol Pathol, 2015. 43(6): p. 776-93.

27. Patro, R., et al., Salmon provides fast and bias-aware quantification of transcript expression. Nat Methods, 2017. 14(4): p. 417-419.

28. Soneson, C., M.I. Love, and M.D. Robinson, Differential analyses for RNA-seq: transcriptlevel estimates improve gene-level inferences. F1000Res, 2015. 4: p. 1521.

29. McKenzie, A.T., et al., Brain Cell Type Specific Gene Expression and Co-expression Network Architectures. Sci Rep, 2018. 8(1): p. 8868.

30. Zhang, Y., G. Parmigiani, and W.E. Johnson, ComBat-seq: batch effect adjustment for RNA-seq count data. NAR Genom Bioinform, 2020. 2(3): p. Iqaa078.

31. Love, M.I., W. Huber, and S. Anders, Moderated estimation of fold change and dispersion for RNA-seq data with DESeq2. Genome Biol, 2014. 15(12): p. 550.

32. Yu, G., et al., clusterProfiler: an R package for comparing biological themes among gene clusters. OMICS, 2012. 16(5): p. 284-7.

33. Szklarczyk, D., et al., STRING v11: protein-protein association networks with increased coverage, supporting functional discovery in genome-wide experimental datasets. Nucleic Acids Res, 2019. 47(D1): p. D607-D613.

34. Han, H., et al., TRRUST V2: an expanded reference database of human and mouse transcriptional regulatory interactions. Nucleic Acids Res, 2018. 46(D1): p. D380-D386.

35. Melendez, R.I., Intermittent (every-other-day) drinking induces rapid escalation of ethanol intake and preference in adolescent and adult C57BL/6J mice. Alcohol Clin Exp Res, 2011. 35(4): p. 652-8. 
36. Priddy, B.M., et al., Sex, strain, and estrous cycle influences on alcohol drinking in rats. Pharmacol Biochem Behav, 2017. 152: p. 61-67.

37. Satta, R., E.R. Hilderbrand, and A.W. Lasek, Ovarian Hormones Contribute to High Levels of Binge-Like Drinking by Female Mice. Alcohol Clin Exp Res, 2018. 42(2): p. 286-294.

38. McDougall, S., et al., Myelination of Axons Corresponds with Faster Transmission Speed in the Prefrontal Cortex of Developing Male Rats. eNeuro, 2018. 5(4).

39. Schuckit, M.A., Low level of response to alcohol as a predictor of future alcoholism. Am J Psychiatry, 1994. 151(2): p. 184-9.

40. Koob, G.F., et al., Neurobiological mechanisms in the transition from drug use to drug dependence. Neurosci Biobehav Rev, 2004. 27(8): p. 739-49.

41. Wachi, M., et al., Effects of ethanol administration on brain neurotensin-like immunoreactivity in rats. Acta Neurol Scand, 1996. 93(2-3): p. 211-4.

42. Campbell, A.D. and V.G. Erwin, Chronic ethanol administration downregulates neurotensin receptors in long- and short-sleep mice. Pharmacol Biochem Behav, 1993. 45(1): p. 95-106.

43. Torruella-Suarez, M.L., et al., Manipulations of Central Amygdala Neurotensin Neurons Alter the Consumption of Ethanol and Sweet Fluids in Mice. J Neurosci, 2020. 40(3): p. 632-647.

44. McCullough, K.M., et al., Molecular characterization of Thy1 expressing fear-inhibiting neurons within the basolateral amygdala. Nat Commun, 2016. 7: p. 13149.

45. Ron, D. and R.O. Messing, Signaling pathways mediating alcohol effects. Curr Top Behav Neurosci, 2013. 13: p. 87-126.

46. Moonat, S., et al., Aberrant histone deacetylase2-mediated histone modifications and synaptic plasticity in the amygdala predisposes to anxiety and alcoholism. Biol Psychiatry, 2013. 73(8): p. 763-73.

47. Peng, B., et al., Role of Alcohol Drinking in Alzheimer's Disease, Parkinson's Disease, and Amyotrophic Lateral Sclerosis. Int J Mol Sci, 2020. 21(7).

48. Chew, L.J., et al., Sox17 Regulates a Program of Oligodendrocyte Progenitor Cell Expansion and Differentiation during Development and Repair. Cell Rep, 2019. 29(10): p. 3173-3186 e7.

49. Chew, L.J., et al., SRY-box containing gene 17 regulates the Wnt/beta-catenin signaling pathway in oligodendrocyte progenitor cells. J Neurosci, 2011. 31(39): p. 13921-35.

50. Maguschak, K.A. and K.J. Ressler, Beta-catenin is required for memory consolidation. Nat Neurosci, 2008. 11(11): p. 1319-26. 


\section{Figure 1.}

(a)

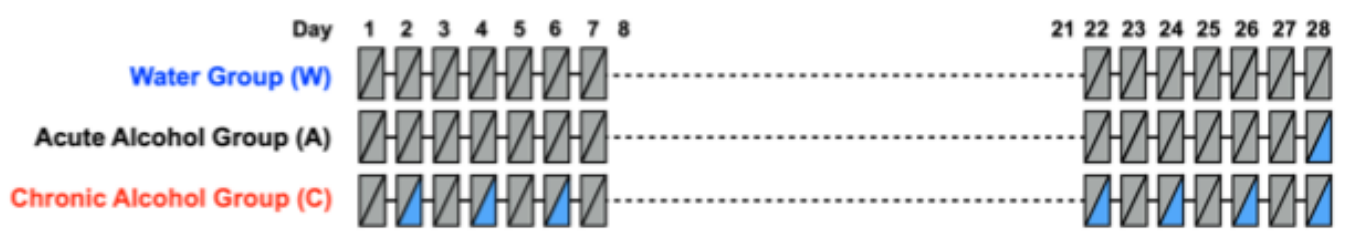

(b)

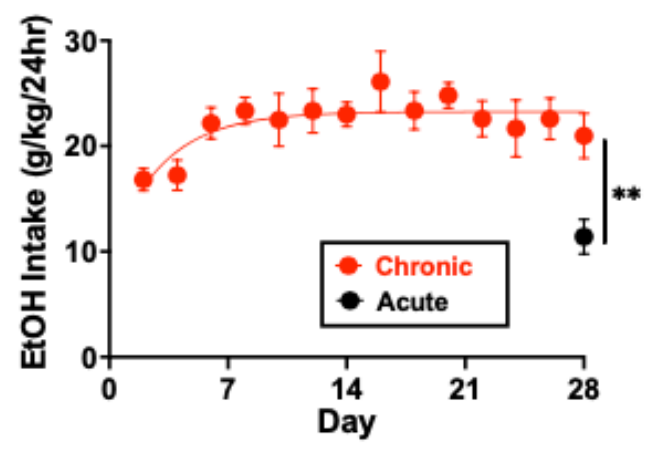

(c)

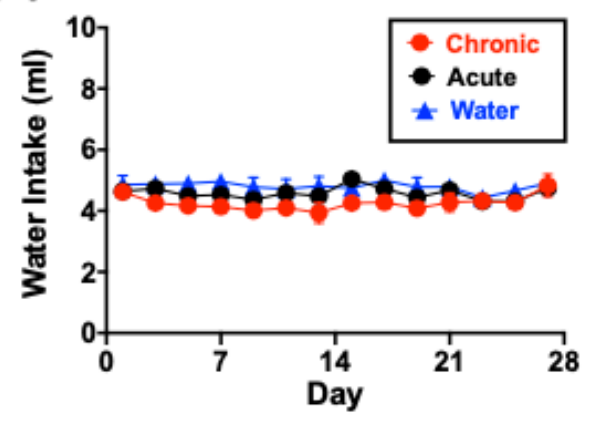

(d)

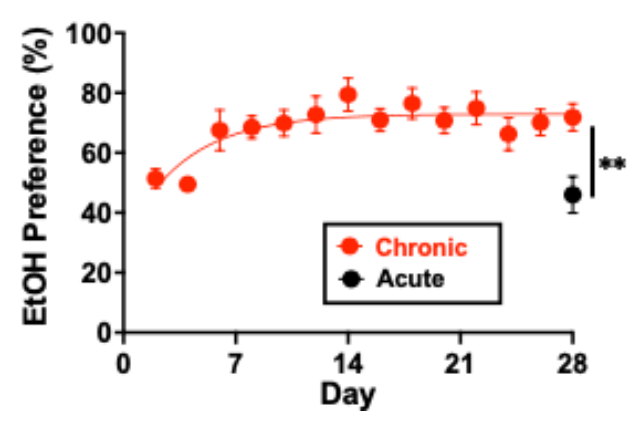

(e)

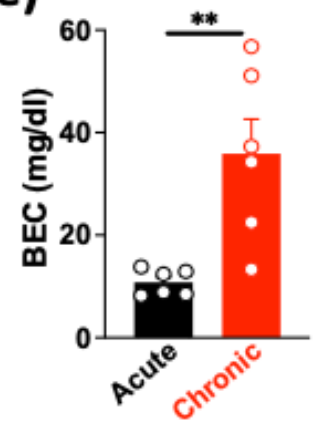

Alcohol Day

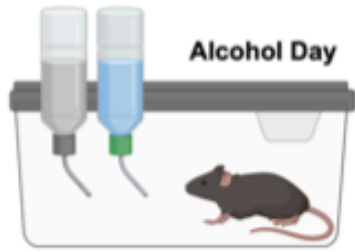

Water Day
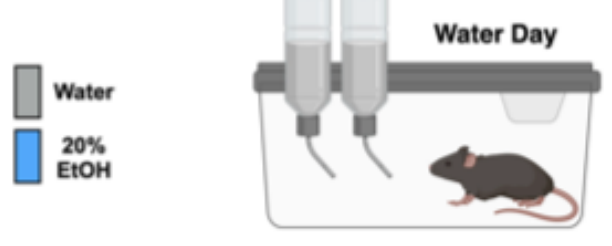

\section{.}


bioRxiv preprint doi: https://doi.org/10.1101/2021.09.07.459347· this version posted September 9, 2021. The copyright holder for this preprint (which was not certified by peer review) is the author/funder, who has granted bioRxiv a license to display the preprint in perpetuity. It is made available under aCC-BY-NC-ND 4.0 International license.

\section{Figure 2.}

(a)

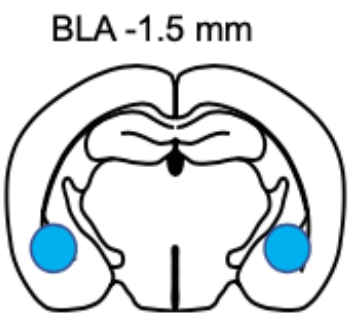

(c)

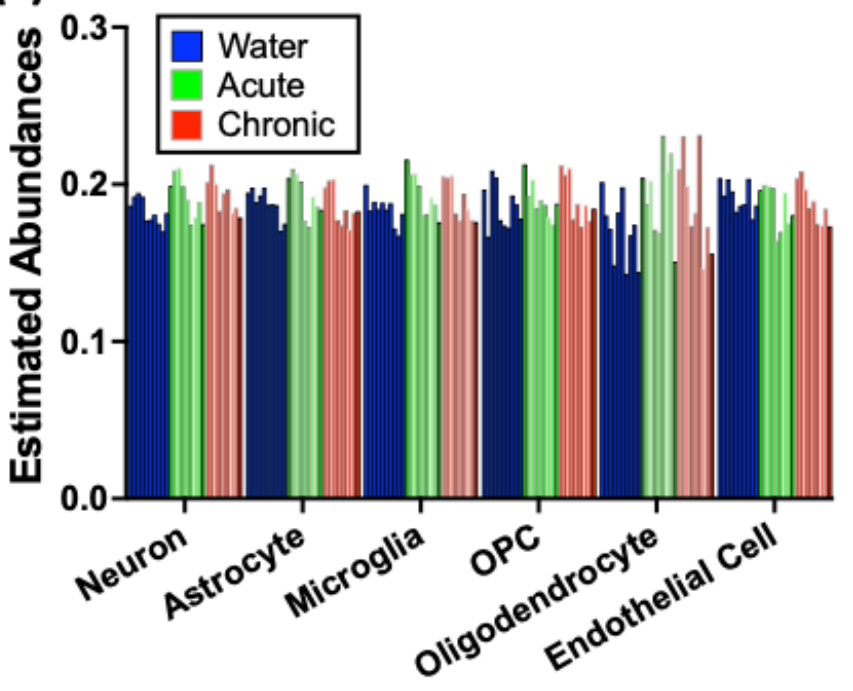

(b)

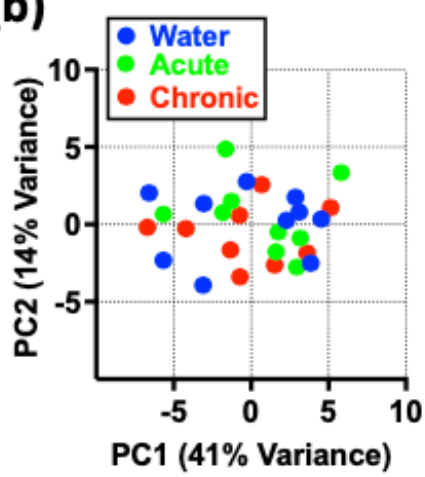




\section{Figure 3.}

(a)

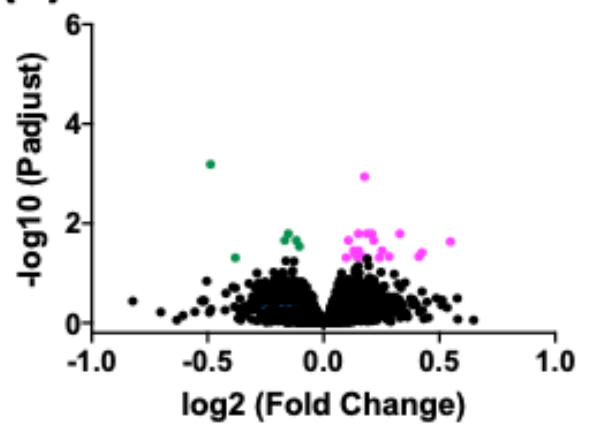

(b)

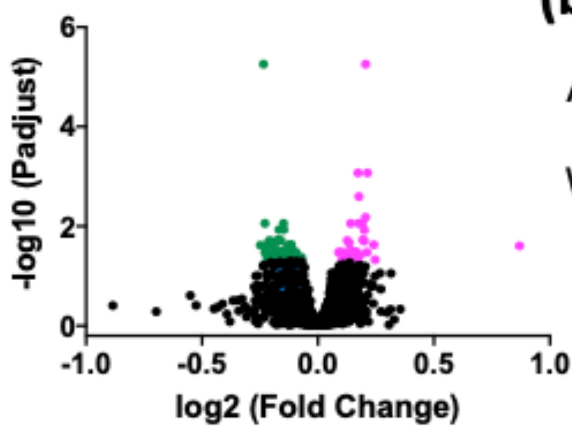

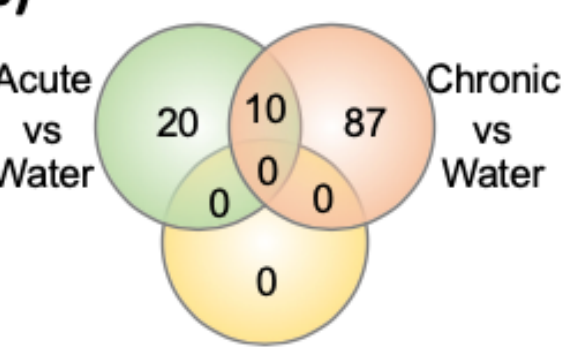

Chronic vs Acute 
bioRxiv preprint doi: https://doi.org/10.1101/2021.09.07.459347· this version posted September 9, 2021. The copyright holder for this preprint (which was not certified by peer review) is the author/funder, who has granted bioRxiv a license to display the preprint in perpetuity. It is made available under aCC-BY-NC-ND 4.0 International license.

\section{Figure 4.}

(a)

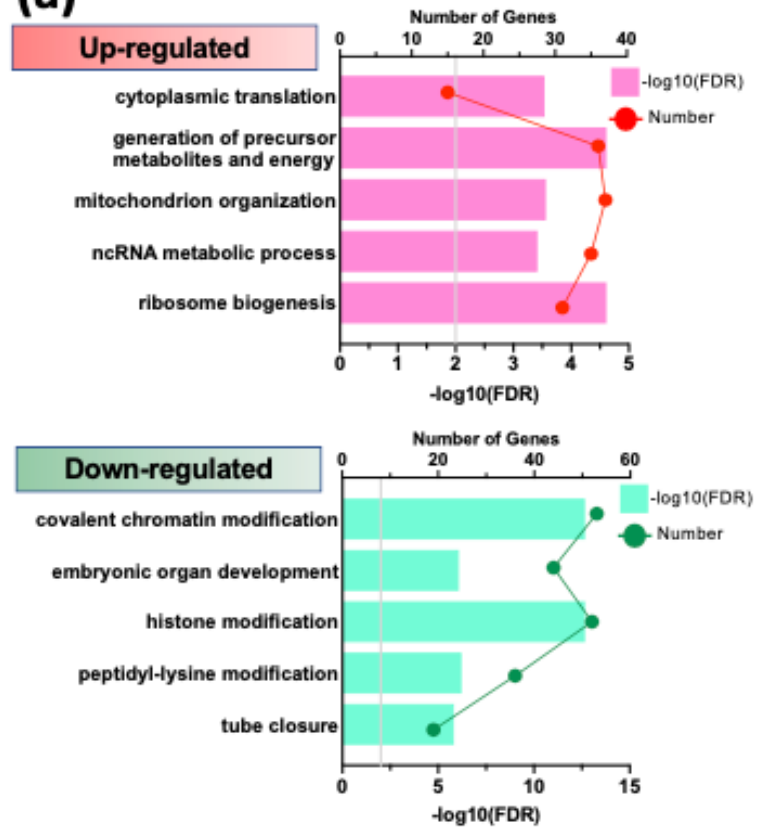

(c)
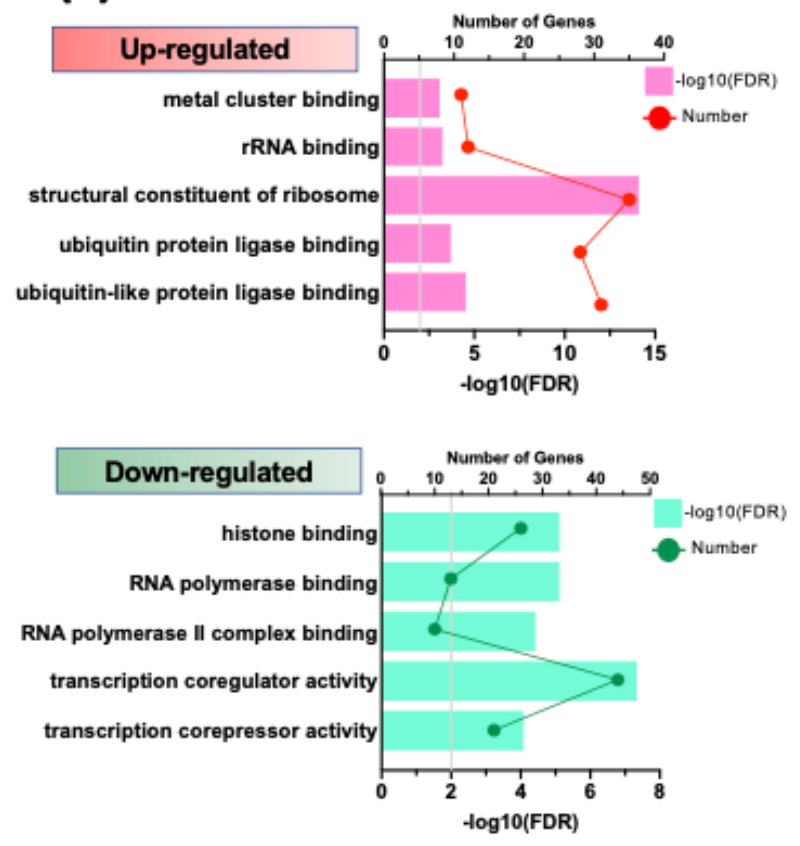

(b)
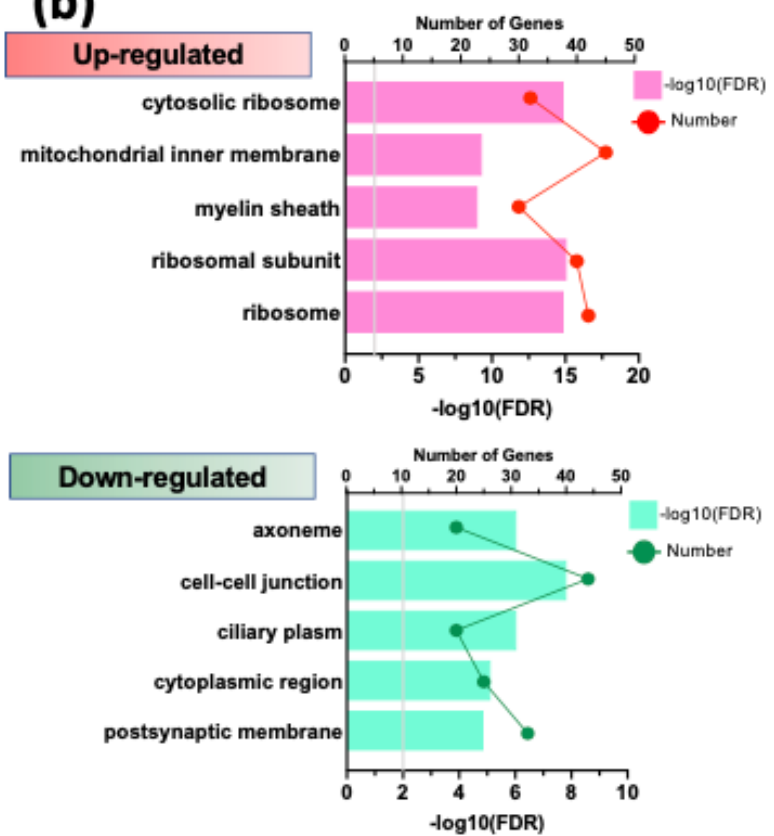

(d)
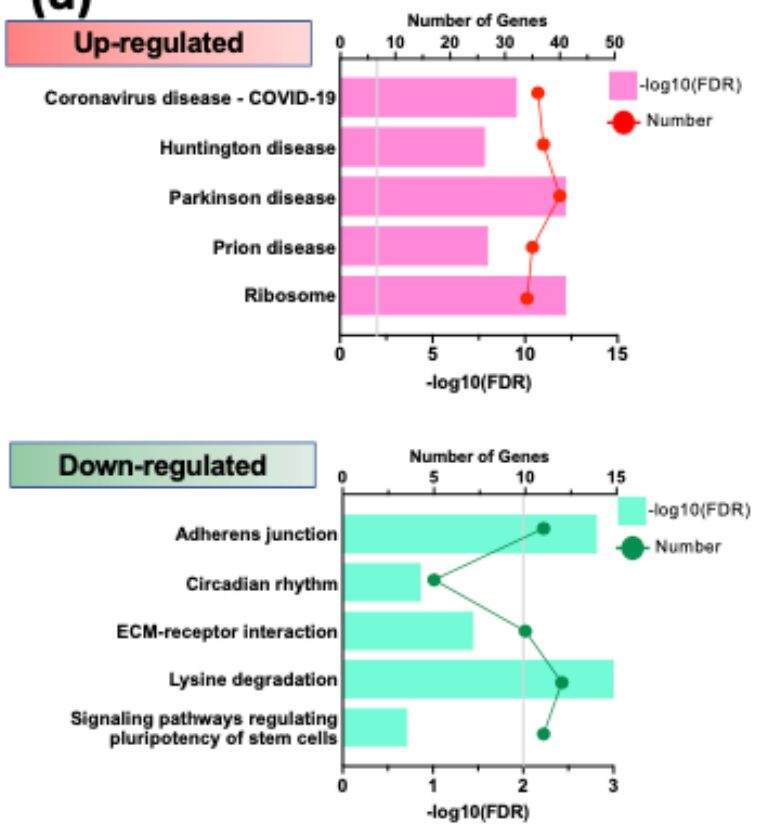
bioRxiv preprint doi: https://doi.org/10.1101/2021.09.07.459347· this version posted September 9, 2021. The copyright holder for this preprint (which was not certified by peer review) is the author/funder, who has granted bioRxiv a license to display the preprint in perpetuity. It is made available under aCC-BY-NC-ND 4.0 International license.

\section{Figure 5.}

(a)
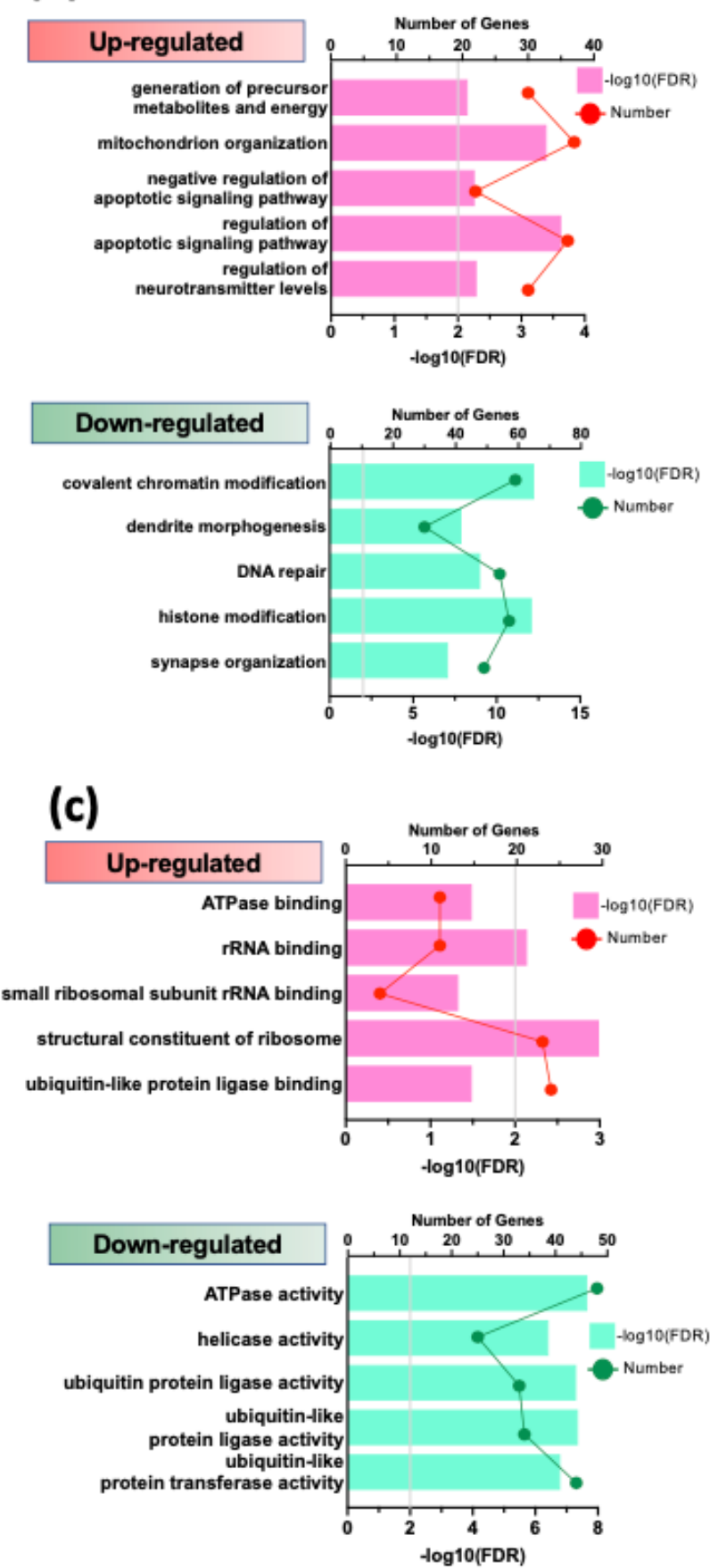

(b)
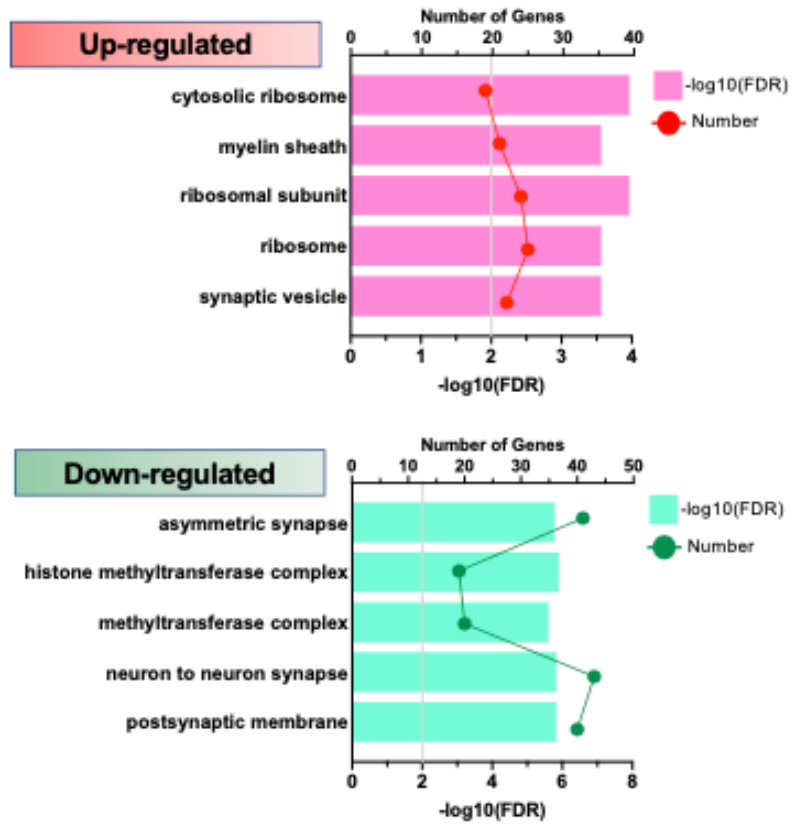

(d)
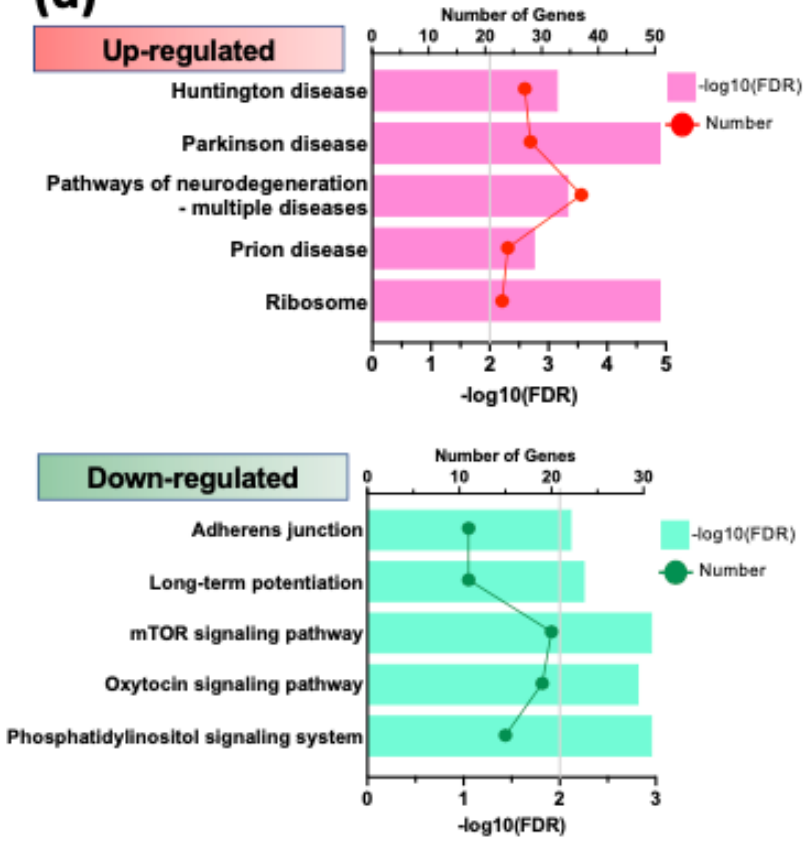
bioRxiv preprint doi: https://doi.org/10.1101/2021.09.07.459347; this version posted September 9, 2021. The copyright holder for this preprint (which was not certified by peer review) is the author/funder, who has granted bioRxiv a license to display the preprint in perpetuity. It is made available under aCC-BY-NC-ND 4.0 International license.

\section{Figure 6.}

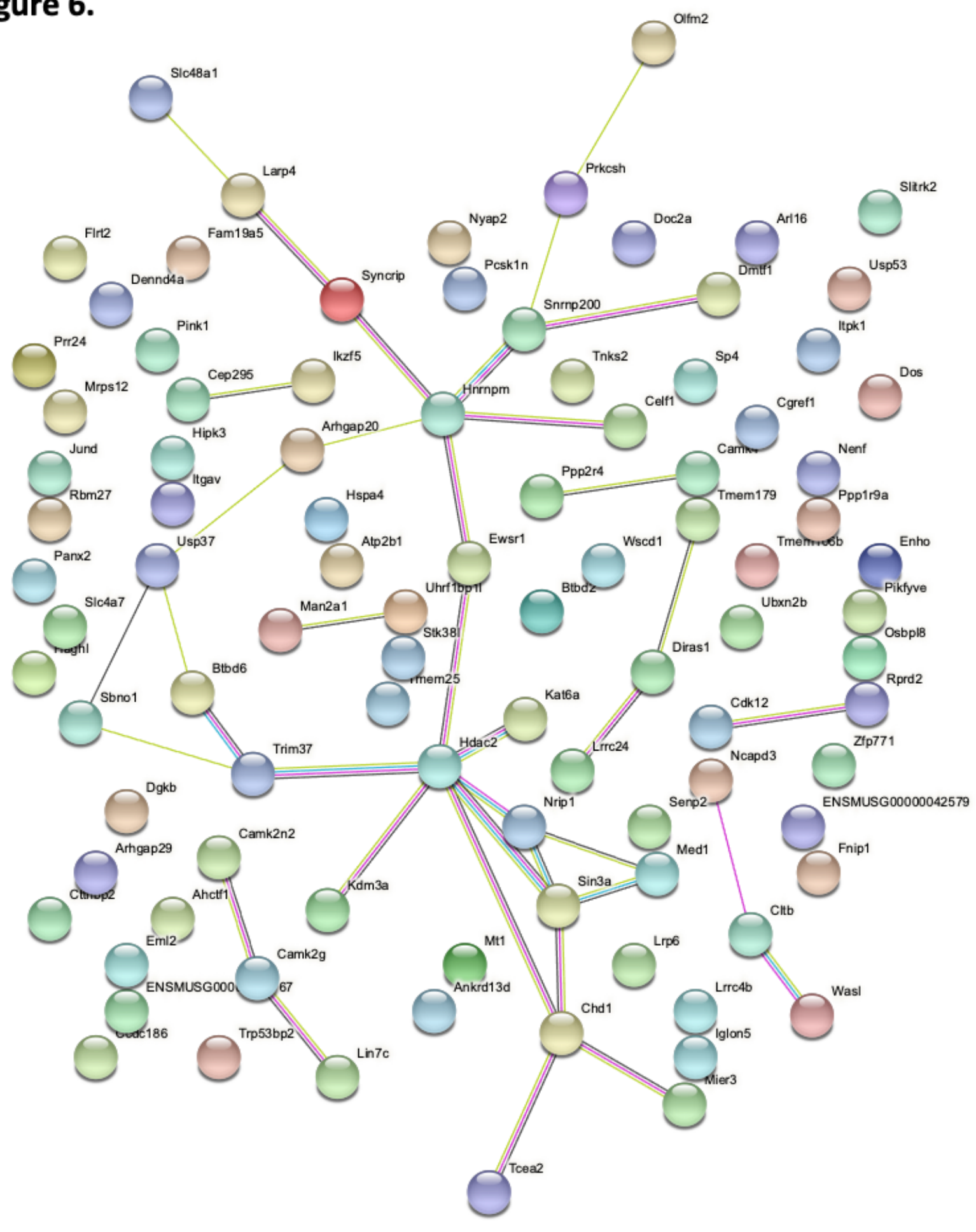


bioRxiv preprint doi: https://doi.org/10.1101/2021.09.07.459347; this version posted September 9,2021. The copyright holder for this preprint (which was not certified by peer review) is the author/funder, who has granted bioRxiv a license to display the preprint in perpetuity. It is made available under aCC-BY-NC-ND 4.0 International license.

Table 1. The 30 Acute Group-assocated DEGs

\begin{tabular}{|c|c|c|c|c|}
\hline Gene Symbol & Gene Name & Fold change $(\log 2)$ & p val & adj. p val \\
\hline 4933427D14Rik & Hypothetical protein LOC9851 & -0.487 & $5.08 \mathrm{E}-08$ & 0.001 \\
\hline Haghl & Hydroxyacylglutathione Hydrolase-Like Protein & 0.178 & $1.81 \mathrm{E}-07$ & 0.001 \\
\hline KIf2 & Kruppel Like Factor 2 & 0.330 & $5.52 \mathrm{E}-06$ & 0.016 \\
\hline Kat6a & Lysine Acetyltransferase 6A & -0.152 & 6.87E-06 & 0.016 \\
\hline Btbd6 & BTB Domain Containing Protein 6 & 0.150 & $7.82 \mathrm{E}-06$ & 0.016 \\
\hline Lrrc24 & Leucine Rich Repeat Containing Protein 24 & 0.188 & $8.48 \mathrm{E}-06$ & 0.016 \\
\hline Mt1 & Matrix Metallopeptidase 14 & 0.208 & 8.76E-06 & 0.016 \\
\hline$K d m 3 a$ & Lysine Demethylase 3A & -0.167 & $1.45 \mathrm{E}-05$ & 0.022 \\
\hline Faap20 & Fanconi Anemia Core Complex Associated Protein 20 & 0.217 & $1.85 \mathrm{E}-05$ & 0.022 \\
\hline Celf1 & CUGBP Elav-Like Family Member 1 & -0.117 & $1.86 \mathrm{E}-05$ & 0.022 \\
\hline Zwint & ZW10 Interacting Kinetochore Protein & 0.108 & $1.88 \mathrm{E}-05$ & 0.022 \\
\hline Nts & Neurotensin & 0.548 & $2.20 \mathrm{E}-05$ & 0.023 \\
\hline Kans/1 & KAT8 Regulatory NSL Complex Subunit 1 & -0.104 & $2.96 \mathrm{E}-05$ & 0.029 \\
\hline$C l t b$ & Clathrin Light Chain B & 0.131 & $3.88 \mathrm{E}-05$ & 0.035 \\
\hline Dusp26 & Dual Specificity Phosphatase 26 & 0.152 & 4.32E-05 & 0.036 \\
\hline Nfkbia & NF-Kappa-B Inhibitor Alpha & 0.253 & 4.45E-05 & 0.036 \\
\hline Srxn1 & Sulfiredoxin 1 & 0.141 & $5.31 E-05$ & 0.039 \\
\hline Btg2 & GF-Inducible Anti-Proliferative Protein PC3 & 0.425 & $5.42 \mathrm{E}-05$ & 0.039 \\
\hline Rpl29 & Ribosomal Protein L29 & 0.138 & $6.26 \mathrm{E}-05$ & 0.041 \\
\hline Diras1 & DIRAS Family GTPase 1 & 0.136 & $6.38 \mathrm{E}-05$ & 0.041 \\
\hline Chga & Chromogranin A & 0.162 & 8.70E-05 & 0.046 \\
\hline Flywch2 & FLYWCH Family Member 2 & 0.411 & 8.95E-05 & 0.046 \\
\hline Pcsk1n & Proprotein Convertase Subtilisin/Kexin Type 1 Inhibitor & 0.144 & $8.98 \mathrm{E}-05$ & 0.046 \\
\hline Lars2 & Leucyl-TRNA Synthetase 2, Mitochondrial & 0.283 & $9.00 \mathrm{E}-05$ & 0.046 \\
\hline Ndufa10 & NADH:Ubiquinone Oxidoreductase Subunit A1 & 0.098 & $1.03 \mathrm{E}-04$ & 0.049 \\
\hline Vstm5 & V-Set And Transmembrane Domain-Containing Protein 5 & 0.241 & $1.06 \mathrm{E}-04$ & 0.049 \\
\hline Ppp1r3f & Protein Phosphatase 1 Regulatory Subunit 3F & 0.169 & $1.07 \mathrm{E}-04$ & 0.049 \\
\hline Slc39a11 & Solute Carrier Family 39 Member 11 & 0.183 & $1.12 \mathrm{E}-04$ & 0.049 \\
\hline Xkr4 & XK Related 4 & -0.380 & $1.15 \mathrm{E}-04$ & 0.049 \\
\hline Dok5 & Docking Protein 5 & 0.189 & $1.25 \mathrm{E}-04$ & 0.052 \\
\hline
\end{tabular}


bioRxiv preprint doi: https://doi.org/10.1101/2021.09.07.459347; this version posted September 9,2021. The copyright holder for this preprint (which was not certified by peer review) is the author/funder, who has granted bioRxiv a license to display the preprint in perpetuity. It is made available under aCC-BY-NC-ND 4.0 International license.

Table 2. The 30 Chronic Group-assocated DEGs

\begin{tabular}{|c|c|c|c|c|}
\hline Gene Symbol & Gene Name & Fold change $(\log 2)$ & p val & adj.p val \\
\hline$K d m 3 a$ & Lysine Demethylase 3A & -0.235 & $1.24 \mathrm{E}-09$ & 0.000 \\
\hline Haghl & Hydroxyacylglutathione Hydrolase-Like Protein & 0.206 & 1.33E-09 & 0.000 \\
\hline Diras1 & DIRAS Family GTPase 1 & 0.172 & $3.92 \mathrm{E}-07$ & 0.001 \\
\hline Lrrc24 & Leucine Rich Repeat Containing Protein 24 & 0.213 & 4.05E-07 & 0.001 \\
\hline Pcsk1n & Proprotein Convertase Subtilisin/Kexin Type 1 Inhibitor & 0.176 & $1.50 \mathrm{E}-06$ & 0.003 \\
\hline Itpk1 & Inositol-Tetrakisphosphate 1-Kinase & 0.205 & $4.71 \mathrm{E}-06$ & 0.007 \\
\hline Cltb & Clathrin Light Chain B & 0.141 & $8.83 \mathrm{E}-06$ & 0.009 \\
\hline$E m / 2$ & Echinoderm MT-Associated Protein (EMAP)-Like Protein 2 & 0.191 & 9.57E-06 & 0.009 \\
\hline Kat6a & Lysine Acetyltransferase 6A & -0.149 & $1.00 \mathrm{E}-05$ & 0.009 \\
\hline Doc2a & Double C2 Domain Alph & 0.176 & $1.11 \mathrm{E}-05$ & 0.009 \\
\hline Arhgap29 & Rho GTPase Activating Protein 29 & -0.228 & $1.16 \mathrm{E}-05$ & 0.009 \\
\hline Larp4 & La Ribonucleoprotein 4 & -0.147 & $1.72 \mathrm{E}-05$ & 0.012 \\
\hline$U b \times n 2 b$ & UBX Domain Protein 2B & -0.168 & $1.82 \mathrm{E}-05$ & 0.012 \\
\hline Inafm1 & InaF Motif Containing 1 & 0.200 & $2.00 \mathrm{E}-05$ & 0.012 \\
\hline Sp4 & Sp4 Transcription Factor & -0.172 & $3.49 \mathrm{E}-05$ & 0.019 \\
\hline Mt1 & Matrix Metallopeptidase 14 & 0.194 & $3.56 \mathrm{E}-05$ & 0.019 \\
\hline Arhgap20 & Rho GTPase Activating Protein 20 & -0.210 & $3.92 \mathrm{E}-05$ & 0.019 \\
\hline Ankrd13d & Ankyrin Repeat Domain 13D & 0.126 & 4.18E-05 & 0.019 \\
\hline$D g k b$ & Diacylglycerol Kinase Beta & -0.159 & 4.37E-05 & 0.019 \\
\hline Enho & Energy Homeostasis-Associated Protei & 0.199 & 4.75E-05 & 0.020 \\
\hline Usp53 & Ubiquitin Specific Peptidase 53 & -0.197 & $5.10 \mathrm{E}-05$ & 0.020 \\
\hline Osbp/8 & Oxysterol Binding Protein Like 8 & -0.210 & $5.58 \mathrm{E}-05$ & 0.021 \\
\hline Btbd6 & BTB/POZ Domain-Containing Protein 6 & 0.135 & 5.93E-05 & 0.022 \\
\hline Nenf & Neudesin Neurotrophic Factor & 0.241 & $6.77 \mathrm{E}-05$ & 0.024 \\
\hline Cep295 & Centrosomal Protein 295 & -0.186 & 7.22E-05 & 0.024 \\
\hline Tmem106b & Transmembrane Protein 106B & -0.119 & 7.31E-05 & 0.024 \\
\hline Hipk3 & Homeodomain Interacting Protein Kinase 3 & -0.114 & $7.58 \mathrm{E}-05$ & 0.024 \\
\hline Pcdhgb7 & Protocadherin Gamma Subfamily B, 7 & -0.248 & 7.95E-05 & 0.024 \\
\hline Fnip1 & Folliculin Interacting Protein 1 & -0.128 & $9.00 \mathrm{E}-05$ & 0.025 \\
\hline Med1 & Mediator Complex Subunit 1 & -0.132 & 9.17E-05 & 0.025 \\
\hline
\end{tabular}


bioRxiv preprint doi: https://doi.org/10.1101/2021.09.07.459347; this version posted September 9, 2021. The copyright holder for this preprint (which was not certified by peer review) is the author/funder, who has granted bioRxiv a license to display the preprint in perpetuity. It is made available under aCC-BY-NC-ND 4.0 International license.

Table 3. Candidate Upstream Transcription Factors

\begin{tabular}{|c|c|c|c|c|c|}
\hline $\begin{array}{r}\text { Drinking } \\
\text { Condition }\end{array}$ & Gene Symbol & Gene Name & $\begin{array}{r}\text { Actual } \\
\text { Targets }\end{array}$ & p-val & z-score \\
\hline \multirow{4}{*}{ Acute } & Taf3 & TATA-Box Binding Protein Associated Factor 3 & 2 & $1.04 \mathrm{E}-04$ & 16.02 \\
\hline & $c-J u n$ & Jun Proto-Oncogene, AP-1 Transcription Factor Subunit & 7 & $2.94 \mathrm{E}-04$ & 5.76 \\
\hline & $c-F o s$ & Fos Proto-Oncogene, AP-1 Transcription Factor Subunit & 5 & 1.87E-04 & 5.27 \\
\hline & Sox17 & SRY (Sex Determining Region Y)-Box Transcription Factor 17 & 22 & 3.60E-04 & 3.63 \\
\hline \multirow{17}{*}{ Chronic } & Rbpj & Recombination Signal Binding Protein for Immunoglobulin Kappa J Region & 58 & 2.27E-11 & 7.18 \\
\hline & Sox17 & SRY (Sex Determining Region Y)-Box Transcription Factor 17 & 69 & $4.86 \mathrm{E}-11$ & 6.70 \\
\hline & Foxp3 & Forkhead Box P3 & 57 & 4.62E-08 & 5.69 \\
\hline & Tal1 & TAL BHLH Transcription Factor 1, Erythroid Differentiation Factor & 61 & $9.83 \mathrm{E}-08$ & 5.45 \\
\hline & Creb1 & CAMP Responsive Element Binding Protein 1 & 44 & $1.29 \mathrm{E}-07$ & 5.74 \\
\hline & Ets1 & ETS Proto-Oncogene 1, Transcription Factor & 53 & $9.50 \mathrm{E}-07$ & 5.09 \\
\hline & $c-M y c$ & MYC Proto-Oncogene, BHLH Transcription Factor & 37 & $6.78 \mathrm{E}-05$ & 4.22 \\
\hline & Runx1 & Runt-Related Transcription Factor 1 & 46 & 1.17E-04 & 3.94 \\
\hline & Gata-2 & GATA Binding Protein 2 & 23 & 1.63E-04 & 4.20 \\
\hline & $E 2 f 1$ & E2F Transcription Factor 1 & 37 & 1.79E-04 & 3.92 \\
\hline & $Z f x$ & Zinc Finger Protein X-Linked & 23 & 2.20E-04 & 4.10 \\
\hline & Gabp & GA Binding Protein Transcription Factor Subunit Alpha & 35 & 3.97E-04 & 3.69 \\
\hline & Cebpe & CCAAT/Enhancer Binding Protein (C/EBP), Epsilon & 4 & 6.07E-04 & 5.85 \\
\hline & Yy1 & YY1 Transcription Factor & 13 & 7.79E-04 & 3.95 \\
\hline & Ash2 & ASH2 Like, Histone Lysine Methyltransferase Complex Subunit & 21 & $2.54 \mathrm{E}-03$ & 3.21 \\
\hline & Glis3 & GLIS Family Zinc Finger 3 & 20 & $2.82 \mathrm{E}-03$ & 3.19 \\
\hline & Klfg & Kruppel Like Factor 9 & 3 & 3.47E-03 & 4.93 \\
\hline
\end{tabular}


bioRxiv preprint doi: https://doi.org/10.1101/2021.09.07.459347· this version posted September 9, 2021. The copyright holder for this preprint (which was not certified by peer review) is the author/funder, who has granted bioRxiv a license to display the preprint in perpetuity. It is made available under aCC-BY-NC-ND 4.0 International license.

Table 4. Validation of DEGs by qPCR

\begin{tabular}{lccc|ccc}
\hline & \multicolumn{2}{c|}{ RNA-seq } & \multicolumn{3}{c}{ qPCR } \\
\hline & \multirow{2}{*}{ Gene } & \multicolumn{2}{c}{ Fold change (log2) } & \multicolumn{3}{c}{ Fold change } \\
\cline { 2 - 7 } & & Acute & Chronic & Water & Acute & Chronic \\
\hline up-regulated & Bc1 & 0.001 & 0.223 & $1.00 \pm 0.11$ & n.a. & $1.27 \pm 0.13$ \\
& Btg2 & 0.425 & 0.206 & $1.00 \pm 0.09$ & $1.40 \pm 0.15^{*}$ & n.a. \\
& Haghl & 0.178 & 0.205 & $1.00 \pm 0.10$ & $1.35 \pm 0.10^{*}$ & $1.57 \pm 0.14^{* *}$ \\
& Lrrc24 & 0.188 & 0.213 & $1.00 \pm 0.13$ & $1.37 \pm 0.10^{*}$ & $1.04 \pm 0.12$ \\
& Nenf & 0.200 & 0.241 & $1.00 \pm 0.09$ & n.a. & $1.34 \pm 0.10^{*}$ \\
& Nts & 0.548 & 0.239 & $1.00 \pm 0.08$ & $1.52 \pm 0.18^{*}$ & n.a. \\
\hline down-regulated & Kdm3a & -0.167 & -0.235 & $1.00 \pm 0.09$ & $0.67 \pm 0.07^{*}$ & $0.71 \pm 0.05^{*}$ \\
\hline
\end{tabular}

